\title{
$\mathrm{PO}$ 기법을 이용한 부분 코팅된 전기적 대형물체의 ISAR 해석 방법
}

\author{
노영훈 ${ }^{1)} \cdot$ 김우빈 $^{1)} \cdot$ 육종관 $\left.{ }^{*}, 1\right) \cdot$ 홍익표 $^{2)} \cdot$ 김윤재 ${ }^{3)} \cdot$ 오원석 ${ }^{3)}$ \\ 1) 연세대학교 전기전자공학과 \\ 2) 공주대학교 정보통신공학부 \\ 3) 국방과학연구소 항공기술연구원
}

\section{Method of Analyzing the ISAR image of Electrically Large Objects Partially Coated with RAM Using PO Technique}

\author{
Yeong-Hoon Noh ${ }^{1)} \cdot$ Woobin $\mathrm{Kim}^{1)} \cdot$ Jong-Gwan Yook $^{*}{ }^{1)}$ · Ic-Pyo Hong ${ }^{2)}$. \\ Yoon-Jae $\mathrm{Kim}^{3)}$. Wonseok $\mathrm{Oh}^{3)}$ \\ 1) Department of Electric and Electronic Engineering, Yonsei University, Korea \\ ${ }^{2)}$ Department of Information and Communication Engineering, Kongju National University, Korea \\ ${ }^{3)}$ Aerospace Technology Research Institute, Agency for Defense Development, Korea
}

(Received 17 April 2020 / Revised 4 June 2020 / Accepted 26 June 2020)

\begin{abstract}
This paper presents an asymptotic analysis method using the PO(physical optics) approximation technique to analyze the scattering contribution of an electrically large object partially coated with a radar absorbing material(RAM). By using the feature of the PO technique that can calculate the equivalent current value for each mesh independently, instead of analyzing the entire structure, scattering analysis was performed only by calculating the current on the area where the RAM coating is applied. By the numerical examples, the accuracy and the computation time of the proposed method were verified, and the computational efficiency of inverse synthetic aperture radar(ISAR) of the electrically large objects that require enormous resources is improved.
\end{abstract}

Key Words : RAM(레이다 흡수 물질), ISAR(역합성 개구면 레이다), RCS(레이다 반사 면적), $\mathrm{PO}$ (물리 광학법), Electromagnetic Scattering(전자기 산란), Stealth Technologies(스텔스 기술)

\section{1. 서 론}

\footnotetext{
${ }^{*}$ Corresponding author, E-mail: jgyook@yonsei.ac.kr Copyright (c) The Korea Institute of Military Science and Technology
}

항공기, 함정 등 레이다 표적의 생존성 향상을 위해 다양한 스텔스 관련 기술들이 활발하게 개발되고 있 다. 그중에서도 점차 고도화되는 multi-static 레이다 탐지 시스템에 대항한 피 탐지 감소 방안으로 레이다 
흡수 물질(Radar Absorbing Materials, RAM), 레이다 흡수 구조(Radar Absorbing Structures, RAS)에 대해 널 리 연구되고 있으며, 최근에는 레이다 표적에 전파 흡 수 재료를 적용한 구조에 대한 성능 검증 연구가 중 점적으로 연구되고 있다 ${ }^{[1-3]}$.

전파 흡수 재료를 실 적용함에 있어서 현실적인 한계점이 존재한다. 대표적인 레이다 표적인 스텔스 항공기의 경우, 전체 면적에 레이다 흡수체를 적용하 게 되면 하중의 증가 및 운용상의 문제가 발생할 수 있다. 또한, 비행 중 공기 마찰에 의해 흡수체 코팅이 훼손될 수 있어 정기적인 점검을 필요로 하기 때문에 경제성을 고려해 레이다 산란 신호에 기여도가 높은 부위를 탐색하고 해당 부위에 선택적으로 적용할 필 요가 있다. 이를 위해 레이다 표적 인식 및 분류에 널 리 활용되는 역합성 개구면 레이다(Inverse Synthetic Aperture Radar) 영상을 이용해 range 및 cross-range의 $2 \mathrm{D}$ 거리 영역 상에서 산란 세기 및 위치를 계산할 수 있다 ${ }^{[4,5]}$.

ISAR 개념 상 해상도 높은 영상을 만들기 위해서 는 광대역 주파수와 넓은 관측 각도에 대한 산란파 결과를 확보해야 하므로, 표적의 $\mathrm{CAD}$ 모델이 있다면 간편하게 다양한 조건에서 시률레이션을 진행할 수 있는 전자기 수치해석이 주로 이용되고 있다. 현재 Multilevel Fast Multipole Method(MLFMM), High-Order Basis Function(HOBF) ${ }^{[6-8]}$ 등의 full-wave 시뮬레이션 기 반 고성능 알고리즘이 개발 및 상용화되어 있지만 해 석 대상의 전기적 크기가 커질수록 계산 자원 및 시 간이 급격히 증가하는 문제가 있다. 이에 대한 대안 으로 고주파 대역에 특화된 물리 광학법(Physical Optics, PO)과 같은 근사 방법 ${ }^{[9-12]}$ 이 주로 사용되지만, 레이다 탐지 주파수 대역이 높아지고 해석 표적의 크 기가 커짐에 따라 많은 unknown이 생성되어 수치해 석을 위해 무수히 많은 계산 자원을 확보해야하는 어 려움이 있다.

본 논문에서는 표적에 실 적용된 전파 흡수 재료의 산란 특성과 산란 기여도(표적의 부위별 산란 크기)를 효율적으로 계산할 수 있는 $\mathrm{PO}$ 를 응용한 우회 해석 방법을 제시한다. ISAR 도출 과정에서 $\mathrm{PO}$ 를 이용해 흡수체 코팅 부위의 등가 전류를 분리해 계산할 수 있는 이론적 배경을 제시하고 전기적 대형물체의 산 란해석이 필연적으로 가지는 막대한 계산시간의 한계 를 개선하였다. 스텔스 항공기(1 GHz 대역)와 Missile (10 GHz 대역)에 레이다 흡수체를 적용한 후, 기존의
방법과 제안한 방법 간의 해석 결과의 정확도 및 해 석 시간을 비교, 분석하여 제안 방법의 효율성을 검증 하였다.

\section{2. 이론적 배경 및 해석 방법}

\subsection{ISAR를 이용한 산란 기여도 예측}

고정된 레이다 표적에 의해 산란된 전자기파는 주 파수에 무관하고 등방성을 가지는 점 산란 원들의 집 합으로 나타낼 수 있다다. 이를 수식으로 나타내면 아 래와 같다.

$E^{s}(k) \simeq \sum_{i=1}^{N} A_{i} e^{j 2 \pi\left(\frac{2 f}{c}\right) x_{i}}$

$E^{s}(k)$ 는 주파수에 따른 산란파의 전계 값을 의미하 며, $c$ 는 빛의 속도(propagation velocity), $f$ 는 입사파의 주파수를, $k=\frac{2 \pi f}{c}$ 는 전파상수를 말한다. 이와 같이 점 산란 원들에 의해 발생되는 원거리 장으로 산란파 의 세기 및 위상 정보를 얻을 수 있다. 이것을 역 푸 리에 변환시키면 식 (2)과 같이 위치 $x_{i}$ 에서의 점 산 란원의 세기 $A_{i}$ 를 알 수 있고 이를 통해 주요 산란 지점과 산란 기여도를 예측할 수 있다.

$$
\begin{aligned}
F^{-1}\left[E^{s}(k)\right] & =\int_{-\infty}^{\infty} d\left(\frac{2 f}{c}\right) E^{s}(k) e^{-j 2 \pi\left(\frac{2 f}{c}\right) x} \\
& =\int_{-\infty}^{\infty} d\left(\frac{2 f}{c}\right) \sum_{i=1}^{N} A_{i} e^{-j 2 \pi\left(\frac{2 f}{c}\right)\left(x-x_{i}\right)} \\
& =\sum_{i=1}^{N} A_{i} \delta\left(x-x_{i}\right)=R P(x)
\end{aligned}
$$

$F^{-1}[]$ 는 역 푸리에 변환을, $\delta(x)$ 는 Dirac delta 함 수를 의미한다. $R P(x)$ 는 $1 \mathrm{D}$ range profile이라고 하 며 Fig. 1(a)과 같이 일차원 거리에 대한 산란파의 발 생 위치와 세기를 의미한다. 작은 대역폭 및 작은 관 측 각을 가진 경우에, 식 (3)과 같이 수평방향 각도 (azimuth angle)에 대한 산란파로부터 얻은 cross-range profile을 추가하면 이차원 거리에 대한 산란 원 분포 를 계산할 수 있고 이를 2D ISAR image라고 한다 (Fig. 1(b) $)^{[13]}$. 
(a)

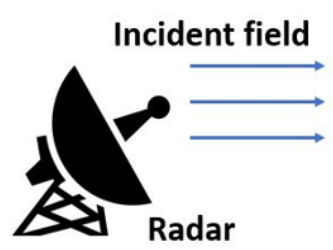

Scattered field

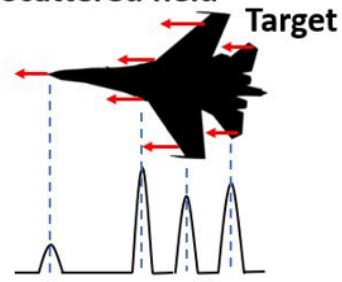

Range profile

(b)

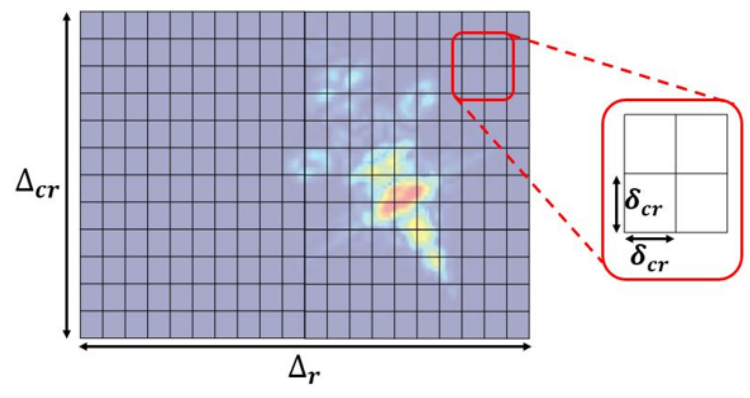

Fig. 1. Concepts of ISAR (a) 1D range profile, (b) range and cross-range profile of $2 \mathrm{D}$ ISAR

$$
\begin{array}{r}
\operatorname{ISAR}(x, y)=\iint_{-\infty}^{\infty} d\left(\frac{2 f}{c}\right) d\left(\frac{k_{c} \phi}{\pi}\right) E^{s}(k, \phi) \\
\cdot e^{-j 2 \pi\left(\frac{2 f}{c}\right) x} e^{-j 2 \pi\left(\frac{k_{c} \phi}{\pi}\right) y}
\end{array}
$$

$\phi$ 는 수평 입사각을, $k_{c}$ 는 해석 중심 주파수에 대한 파수를 의미한다. $\operatorname{ISAR}(x, y)$ 는 주파수, 입사각을 변 수로 한 산란 전기장의 역 푸리에 변환으로 계산하므 로 주파수 대역폭 $(B W)$ 과 총 입사각도 $(\Omega)$ 는 $(x, y)$ 영 역 상에 값들의 간격인 해상도와 총 범위를 결정하는 데에 중요한 요인이 된다. ${ }^{[14]}$

$\delta_{r}=\frac{c}{2 B W}$ and $\delta_{c r}=\frac{\lambda_{c}}{2 \Omega}$

$\delta_{r}, \delta_{c r}$ 은 각각 range, cross-range 정보의 해상도를 의 미하고 $\Delta_{r}, \Delta_{c r}$ 은 각각 range, cross-range의 범위를 의 미한다. $\lambda_{c}$ 는 중심 주파수 $f_{c}$ 에 해당하는 파장을 나타 낸다. 식 (4)에 의해 산란 위치에 따른 기여도를 정확 히 판단하기 위해서는 충분한 해상도를 고려해서 ISAR image를 도출해야 한다.

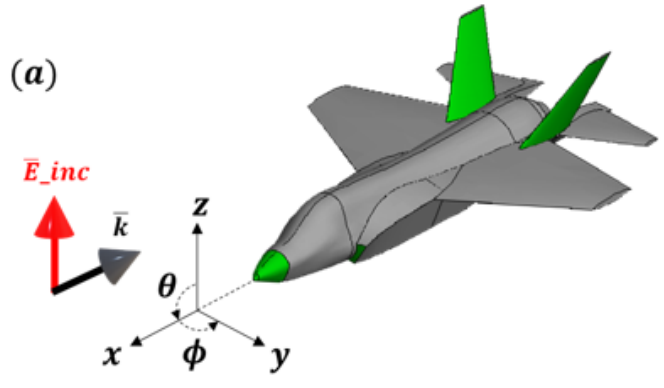

(b)
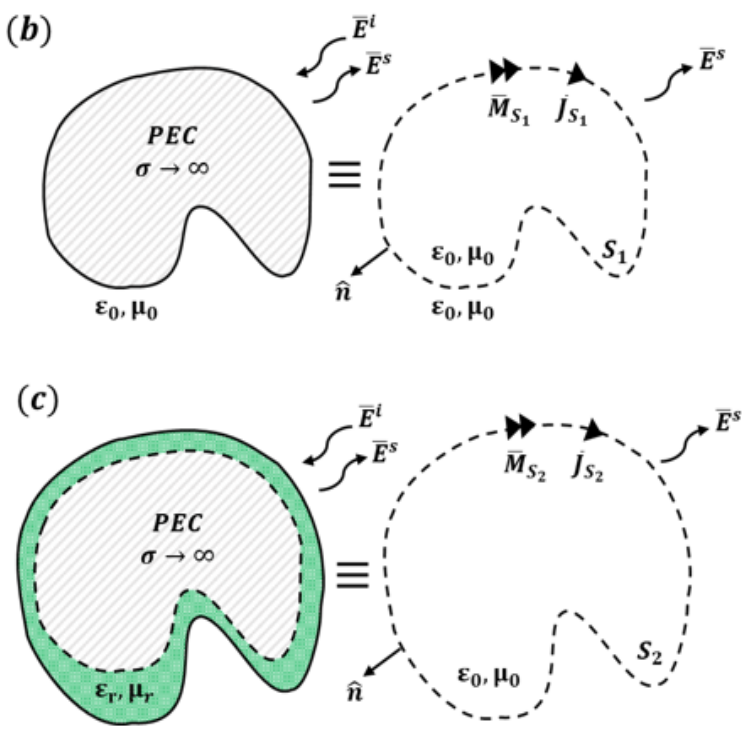

Fig. 2. Scattering problem model (a) analysis setup: incident wave, radar target, axis setup, (b) equivalent boundary problem of PEC target, (c) equivalent boundary problem of target coated with RAM

\subsection{PO 기법을 이용한 ISAR 해석}

Fig. 2(a)는 PEC 영역 $\left(S_{1}\right.$, 회색 영역)과 유전체가 코 팅된 영역 $\left(S_{2}\right.$, 초록색 영역)으로 이루어진 레이다 표 적에 전자기파를 입사하는 경우를 표현한 것이고, Fig. 2(b)는 $S_{1}$ 에 대한 산란을, Fig. 2(c)는 $S_{2}$ 에 대한 산란 을 나타낸 것이다.

식 (3)을 이용해 ISAR를 얻기 위해서는 $E^{s}(k, \phi)$ 를 계산해야 하며, 이것은 equivalence principle에 의해 자 유공간 상에 존재하는 등가 전류 $\bar{J}_{S}, \bar{M}_{S}$ 에 의해 발생 하는 원전계로 나타낼 수 있다 ${ }^{[15,16]}$. 이를 수식적으로 나타내면 다음과 같다. 


$$
\begin{aligned}
\bar{E}^{s}(k, \phi)= & -\frac{j \omega \mu_{0}}{4 \pi} \int_{S} d S^{\prime}\left(\bar{J}_{S}\left(r^{\prime}\right)\right. \\
& +\frac{1}{k^{2}} \bar{\nabla}^{\prime} \bar{\nabla}^{\prime} \cdot \bar{J}_{S}\left(r^{\prime}\right) \\
& \left.+\frac{1}{j w \mu_{0}} \bar{\nabla}^{\prime} \times \bar{M}_{S}\left(r^{\prime}\right)\right) \frac{e^{-j \bar{k} \cdot \bar{R}}}{R}
\end{aligned}
$$

$\omega(=2 \pi f)$ 는 각주파수, $R\left(=|\bar{R}|=\left|\bar{r}-\overline{r^{\prime}}\right|\right)$ 은 산란 원과 관측 지점 간의 거리이다. 이 때, 입사파의 주파 수 $f$ 가 높아지면 레이다 표적의 파장 대비 크기가 커 지게 되고 표적의 표면상의 모든 위치에 대해 무한한 평면을 가정할 수 있다. 여기에서 $\mathrm{PO}$ 근사 기법에 의 해 등가 표면 전류 $\bar{J}_{S}, \bar{M}_{S}$ 를 표면의 법선벡터 $\hat{n}$ 와 입사 전계 $\bar{E}^{i}$ 및 입사 자계 $\bar{H}^{i}$ 로 나타낼 수 있다 [17,18]. 이를 이용해 Fig. 2(b), (c)의 등가전류를 구하면 다음과 같다.

$$
\begin{array}{ll}
\bar{J}_{S_{1}}=2 \hat{n} \times \bar{H}^{i}\left(r^{\prime}\right) & \text { on } S_{1} \\
\bar{M}_{S_{1}}=-2 \hat{n} \times \bar{E}^{i}\left(r^{\prime}\right)=0 & \text { on } S_{1} \\
\bar{J}_{S_{2}}=2 \Gamma \hat{n} \times \bar{H}^{i}\left(r^{\prime}\right) & \text { on } S_{2} \\
\bar{M}_{S_{2}}=-2 \hat{n} \times \bar{E}^{i}\left(r^{\prime}\right)=0 & \text { on } S_{2}
\end{array}
$$

$\Gamma$ 은 Fresnel 반사 계수로, 입사 전계 (또는 자계)와 산란 전계의 비 $\left(=E^{i} / E^{s}\right)$ 를 의미한다. 식 (6) $S_{1}$ 의 경 우는 $\mathrm{PEC}$ 매질이므로 $\bar{M}_{S}=0$ 이고 $R=1$ (parallel 편 파) or -1 (perpendicular 편파)를 대입해 구할 수 있다. 식 (6)을 식 (5)에 대입하면 아래와 같이 전개된다.

$$
\begin{aligned}
\bar{E}^{s}(k, \phi)= & -\frac{j \omega \mu_{0}}{2 \pi}\left(\int_{S_{1}} d S_{1}{ }^{\prime} \hat{n} \times \bar{H}^{i}\left(r^{\prime}\right) \frac{e^{-j \bar{k} \cdot \bar{R}}}{R}\right. \\
& \left.+\int_{S_{2}} d S_{2}{ }^{\prime} \hat{n} \times \bar{H}^{i}\left(r^{\prime}\right) \Gamma \frac{e^{-j \bar{k} \cdot \bar{R}}}{R}\right)
\end{aligned}
$$

이와 같이 $\mathrm{PO}$ 근사 기법을 통해 레이다 표적을 PEC 영역과 유전체 코팅 영역으로 나눠서 따로 ISAR 정보를 계산할 수 있다. 또한 유전체 코팅 시, 코팅 부위의 표면 전류 값만 변화하므로 표적 전체를 해석 하지 않고 코팅 부위만 해석하여 계산 자원을 줄일 수 있다. 2.3절에서는 이를 활용한 해석 방법 및 순서 를 제안한다.

\section{3 제안하는 ISAR 해석 방법}

본 절에서는 부분적으로 RAM 코팅이 되어 있는 $\mathrm{PEC}$ 재질 레이다 표적의 ISAR 이미지를 도출하는 구 체적인 방법을 설명한다. 식 (7)로부터 레이다 표적에 서 PEC 영역과 코팅 영역은 따로 해석이 가능하다. 그러므로 코팅 영역이 바뀔 때마다 레이다 표적 전체 를 해석하지 않고 코팅 영역만을 해석하여 계산 효율 성을 확보할 수 있다.

전자기 산란해석을 수행하기 위해 상용 소프트웨어 인 $\mathrm{FEKO}$ 의 $\mathrm{PO}$ 근사 기법을 이용하였고, 해석의 단위 가 되는 mesh(또는 facet) 정보에 대한 후처리나 ISAR 이미징은 MATLAB 코드를 작성하였다. Fig. 3은 본 논문에서 제안하는 ISAR 해석 과정을 나타낸 개념도 이다.

\section{- Step 1 : Setup (조건 설정)}

레이다 표적에서 $\mathrm{PEC}$ 영역과 RAM 코팅 영역을 구분하고 해석 주파수, 입사파의 편파 및 입사각 등 의 해석 조건을 설정한다.

- Step 2 : Mesh generation (메쉬 생성) 레이다 표적 $\mathrm{CAD}$ 모델의 코팅 영역에 'Thin Dielectric Sheet(TDS) 옵션을 이용해 RAM 물성을 코팅 설정하고 메쉬를 생성한다.

- Step 3 : Coated model generation (코팅 모델 생성) $\mathrm{PO}$ 근사 기법을 이용한 산란 전계는 입사파의 자 계 값과 입사 지점의 법선 벡터와의 관계에 의해서 결정된다. 즉, 입사파가 도달하는 메쉬에 한해서만 표면 등가 전류 값이 계산될 수 있다. 따라서 Step 2에서 생성한 코팅 영역의 메쉬 중 입사파가 도달 하지 않는 shadowed region에 해당하는 메쉬를 계산 에서 제외한다. 이를 통해 생성된 코팅 모델(b)에 대 해 산란 해석을 진행한다.

- Step 4 : Numerical results (산란 해석 결과) 레이다 표적 전체가 $\mathrm{PEC}$ 로 이루어진 경우(a)에 대 해 산란해석 결과를 사전 확보한다. Step 3에서 구 한 (b)의 각 메쉬 당 등가 전류 값을 (a)에서 해당하 는 메쉬의 등가 전류 값과 교체한다. 완성된 등가 전류 값으로부터 식 (7)에 대입해 산란 원전계를 계 산하고, 식 (3)에 대입해 ISAR 이미지를 도출한다.

3장에서는 본 절에서 제안한 해석 방법을 이용하여 부분 코팅된 레이다 표적의 ISAR 이미지를 우회 해석 한 예시를 제시한다. 임의의 부위에 전파 흡수 특성을 


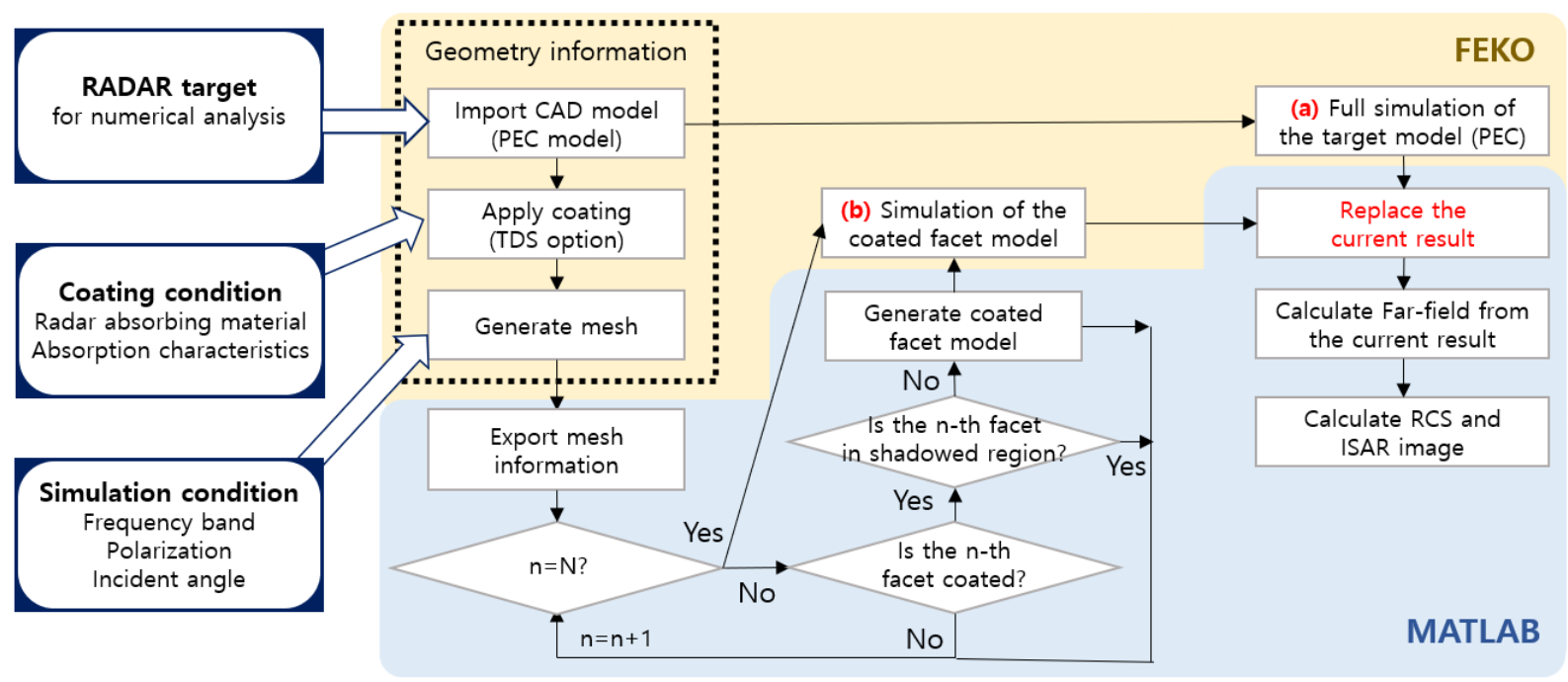

Step 1 : Setup

Step 2 : Mesh generation

Step 3 : Coated model generation

Step 4 : Numerical results

Fig. 3. Conceptual diagram of proposed analysis method

가지는 RAM을 코팅하여, 전체 구조를 해석한 결과와 코팅 영역만 해석해 도출한 결과를 계산속도, 정확도 면에서 비교하였다.

\section{ISAR 산란 해석 결과 및 분석}

시뮬레이션에 사용한 PC 환경은 $\operatorname{Intel}(\mathrm{R}) \operatorname{Xeon}(\mathrm{R})$ CPU E5-2690 v4 2.60GHz (2 Processor), 512 GB RAM 이고, 2장에서 제안한 ISAR 해석 방법을 이용해 두 가지 전기적 대형물체에 대한 산란 기여도 분석을 수 행하였다.

\section{1 시뮬레이션 예시 1: 항공기 모델(1 $\mathrm{GHz}$ 대역)}

Fig. 4(a), (b)는 산란 해석에 사용된 길이 $15.23 \mathrm{~m}$, 폭 $10.06 \mathrm{~m}$ 의 항공기 표적모델로 $x$ 축 방향을 바라보 고 있다. 해석 주파수는 $0.9 \mathrm{GHz}-1.1 \mathrm{GHz}$ 이며 64개 의 주파수에서 해석하였다(대역폭 $0.2 \mathrm{GHz}$, 주파수 간 격 $3.17 \mathrm{MHz}$ ). 입사각의 범위는 $\phi=45^{\circ}-55^{\circ}$ 이며 41 개의 방향에 대해 해석하였다(총 각도 범위 $10^{\circ}$, 각 도 간격 $0.25^{\circ}$ ). 따라서 $2 \mathrm{D}$ ISAR 이미지의 해상도는 $\delta_{r}$ 는 $0.75 \mathrm{~m}, \delta_{c r}$ 는 $0.86 \mathrm{~m}$ 이다.

RAM 물성은 비유전율이 15, Loss tangent가 0.27 , 비투자율이 1, 두께가 $20 \mathrm{~mm}$ 이며, Fig. 4(c)와 같이 해
석 중심 주파수 $1 \mathrm{GHz}$ 에서 $-21 \mathrm{~dB}$ 의 레이다 흡수 특 성을 나타낸다.

Fig. 6은 항공기 모델에 대한 ISAR 이미징 결과를 나타낸 것으로, Fig. 6(a)은 PEC로 이루어진 전체 표적 에 대해 $\mathrm{PO}$ 근사 기법을 이용한 것이다. 위의 해석 조건(해석 주파수대역, 입사각 범위)에서 표면을 $\lambda / 6$ 크기의 메쉬로 분할할 경우 항공기 모델은 199,597개 의 메쉬로 이루어져 있다. ISAR 이미지 상에서 hot spot으로 나타나는 레이돔 부분, 엔진 인렛 부분, 수직 꼬리 날개 부분에서 전자기 산란이 크게 발생하는 것 을 알 수 있고, $\mathrm{RCS}$ 저감을 위해 해당 부분에 RAM 코팅을 적용하였다(Fig. 6(b)). 이 때, RAM 코팅을 적 용한 부위에서 ISAR 세기가 감소했음을 명확하게 확 인할 수 있다. 코팅 해석에 적용한 TDS 기법은 PEC 모델과 동일한 메쉬를 사용하므로 199,597 개의 동일한 unknown 수와 계산 량을 가진다.

Fig. 6(c)은 앞서 제안한 해석 방법을 사용해 RAM 코팅 부위만 해석해 구한 등가전류 값으로 PEC 모델 의 해당 메쉬의 전류 값을 대체해 원전계와 ISAR 이 미지를 계산한 것이다. ISAR 이미지 상에서 Fig. 6(b) 과 동일한 결과를 확인할 수 있고, $6(\mathrm{~b})$ 과 달리 코팅 부위의 22,674개의 메쉬에 대해서만 해석하므로 약 $11.4 \%$ 수준의 적은 계산 자원을 필요로 한다. 

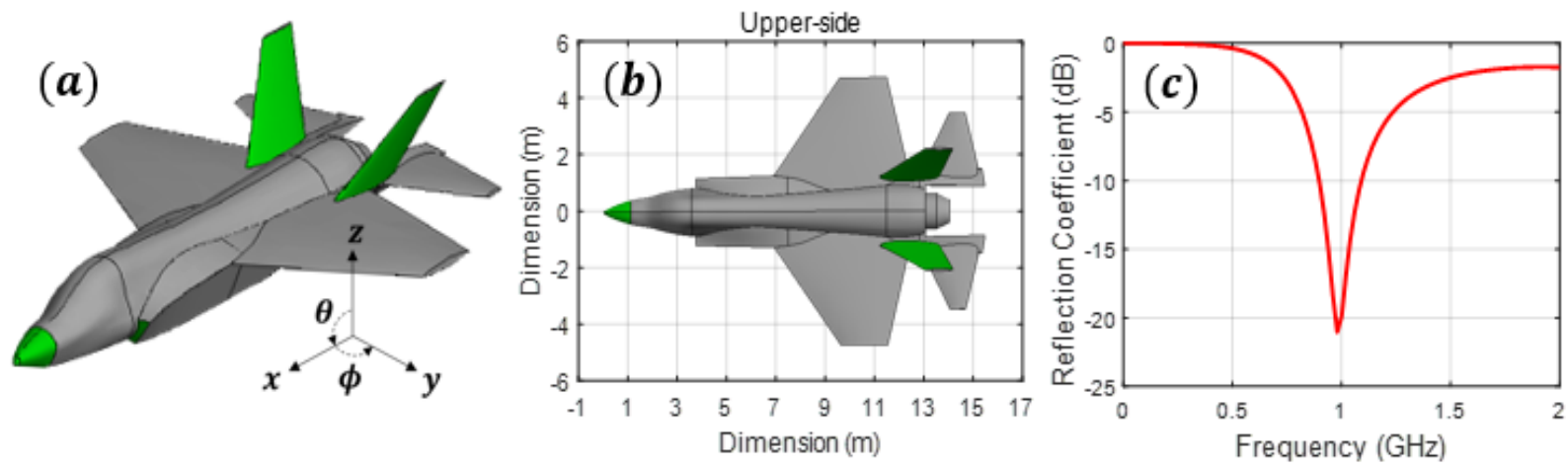

Fig. 4. Simulation model of example 1 (a) aircraft model coated with RAM, (b) geometry of the aircraft, (c) absorption characteristic of the RAM
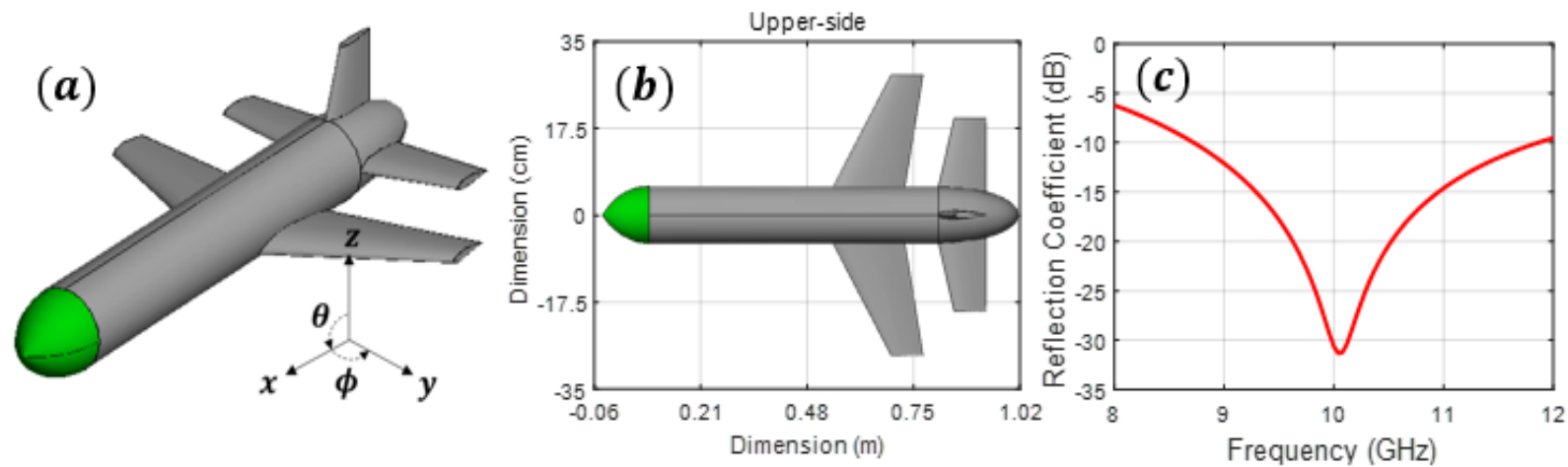

Fig. 5. Simulation model of example 2 (a) missile model coated with RAM, (b) geometry of the missile, (c) absorption characteristic of the RAM

3.2 시뮬레이션 예시 2: Missile 모델(10 GHz 대역) Fig. 5(a), (b)는 산란 해석에 사용된 Missile 모델로 길이 $1 \mathrm{~m}$, 폭 $0.63 \mathrm{~m}$ 의 구조이다. 해석 주파수는 8 $\mathrm{GHz}-12 \mathrm{GHz}$ 이며 81개의 주파수에서 해석하였다(대 역폭 $4 \mathrm{GHz}$, 주파수 간격 $50 \mathrm{MHz}$ ). 입사각의 범위는 $\phi=33^{\circ}-57^{\circ}$ 이며 73 개의 방향에 대해 해석하였다 (총 각도 범위 $24^{\circ}$, 각도 간격 $0.33^{\circ}$ ). 따라서 $2 \mathrm{D}$ ISAR 이미지의 해상도는 $\delta_{r}$ 는 $37.5 \mathrm{~mm}, \delta_{c r}$ 는 $35.8 \mathrm{~mm}$ 이다.

RAM 물성은 비유전율이 7.98, Loss tangent가 0.46, 비투자율이 1, 두께가 $2.7 \mathrm{~mm}$ 이며, Fig. 5(c)와 같이 해석 중심 주파수 $10 \mathrm{GHz}$ 에서 $-31 \mathrm{~dB}$ 의 레이다 흡수 특성을 나타낸다 ${ }^{[19]}$.

Fig. 7은 Missile 모델에 대한 ISAR 이미징 결과를 나타낸 것으로, Fig. 7(a)은 PEC로 이루어진 전체 표적 에 대해 PO 근사 기법을 이용한 것이다. 위의 해석
조건에서 표면을 $\lambda / 6$ 크기의 메쉬로 분할할 경우 77,752 개의 메쉬로 이루어져 있으며 hot spot으로 나타 나는 레이돔 부분에서 전자기 산란이 크게 발생하는 것을 알 수 있다. RCS 저감을 위해 해당 부분에 RAM 코팅을 적용하였다(Fig. 7(b)). 이 때, RAM 코팅 을 적용한 부위에서 ISAR 세기가 감소했음을 뚜렷하 게 확인할 수 있다.

Fig. 7(c)은 앞서 제안한 해석 방법을 사용해 RAM 코팅 부위만 해석해 구한 등가전류 값으로 PEC 모델 의 해당 메쉬의 전류 값을 대체해 원전계와 ISAR 이 미지를 계산한 것이다. ISAR 이미지 상에서 Fig. 7(b) 과 동일한 결과를 확인할 수 있고, 7(b)과 달리 코팅 부위의 4,794개의 메쉬에 대해서만 해석하므로 약 6.2 $\%$ 수준의 적은 계산 자원을 필요로 한다. 

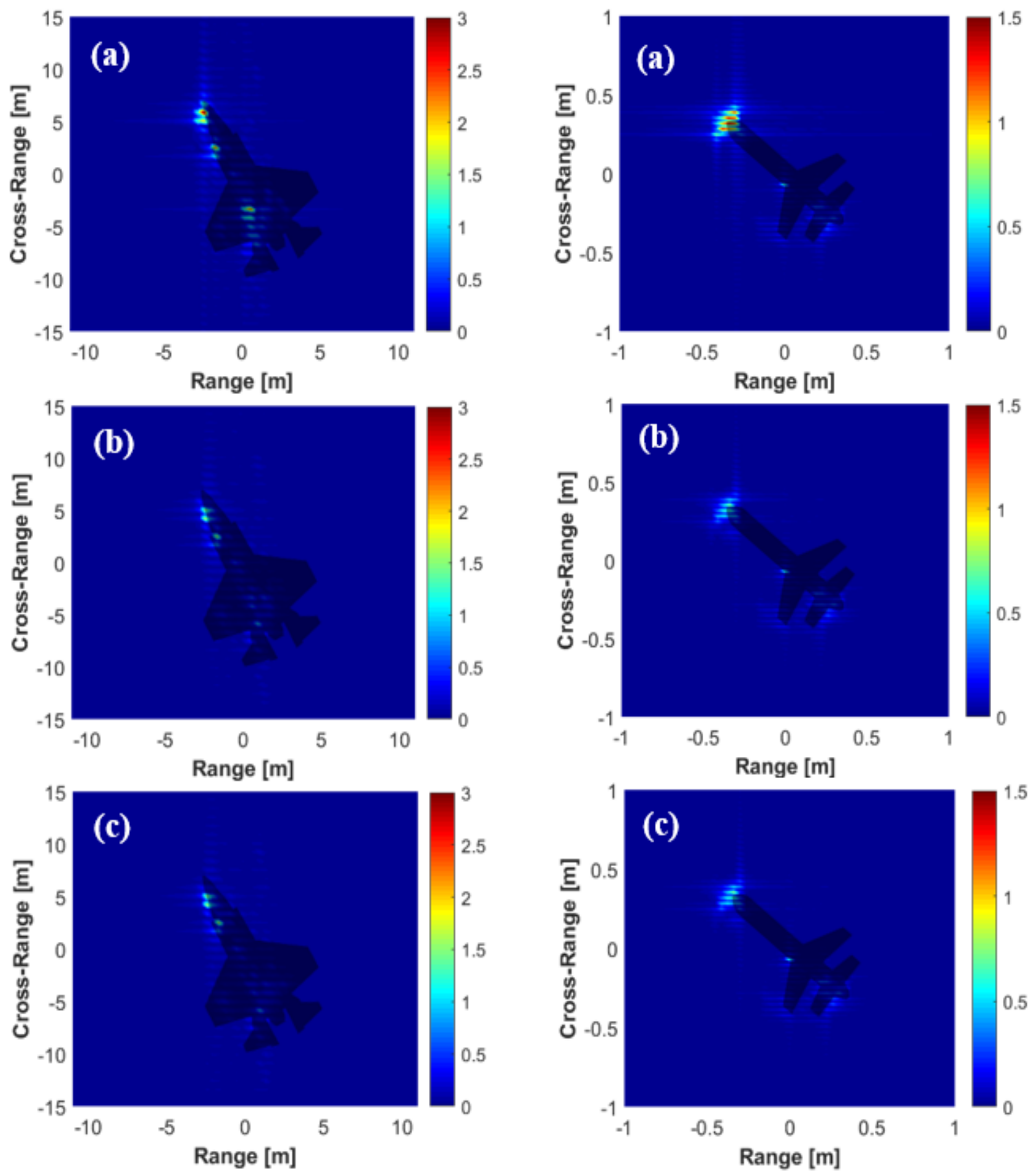

Fig. 6. 2D ISAR image of the aircraft model (a) PEC model, (b) partially coated model (full-simulated), (c) partially coated model (proposed method)

Fig. 7. 2D ISAR image of the missile model (a) PEC model, (b) partially coated model (full-simulated), (c) partially coated model (proposed method) 


\section{3 제안한 해석 방법의 계산 성능}

Table 1은 3.1절, 3.2절의 해석 정확도와 해석 시간 에 대한 성능 결과를 나타낸 것이다. $\mathrm{PO}$ 를 이용한 수 치해석에 사용된 unknown수와 해석 시간이며, 오차 (Mean difference)는 전체를 해석하는 방법과 제안한 방법 간에 특정 주요 산란점들에 대한 ISAR 신호 크 기 차이의 평균을 나타낸 것이다. 해석에 사용한 $\mathrm{PC}$ 의 병렬 core 수는 10 개로 설정하였다.

시뮬레이션 예시 1. 항공기 모델에 대해서 표적 모 델 전체를 해석한 경우에 총 계산 시간 2 시간 12 분이 걸렸으나 제안한 방법의 경우에는 1 시간 4 분이 소요 되어 약 $48 \%$ 수준으로 계산 시간이 감소한 것을 확 인할 수 있다. 또한, 계산에 사용한 총 peak memory가 약 483.8 Mbyte에서 약 74.7 Mbyte로 감소하여 약 $15.4 \%$ 수준으로 개선되었다. 반면에 ISAR 결과상 오 차는 $0.97 \%$ 로, 결과는 동일하게 유지하면서 계산 자 원을 대폭 감소한 것을 알 수 있다.

시뮬레이션 예시 2. Missile 모델에 대해서도 동일한 경향을 확인할 수 있다. 표적 모델 전체를 해석한 경우 에 총 계산 시간 1 시간 51 분, 제안한 방법의 경우에는 21 분이 소요되어 약 $18.9 \%$ 수준으로 현저히 줄어든 것을 확인했고, 계산에 사용한 총 peak memory가 약 176.9 Mbyte에서 약 17.1 Mbyte로 감소하여 약 $9.7 \%$

Table 1. Comparison of the computational performance

\begin{tabular}{|l|c|c|}
\hline & Fig. 6(b) & Fig. 6(c) \\
\hline $\begin{array}{l}\text { The number of unknowns } \\
\text { (the number of mesh) }\end{array}$ & 199,597 & 22,674 \\
\hline Computation time (min) & 132 & 64 \\
\hline $\begin{array}{l}\text { Peak memory usage of all } \\
\text { processes (Mbyte) }\end{array}$ & 483.8 & 74.7 \\
\hline Mean difference (\%) & \multicolumn{2}{|c|}{0.97} \\
\hline & Fig. 7(b) & Fig. 7(c) \\
\hline $\begin{array}{l}\text { The number of unknowns } \\
\text { (the number of mesh) }\end{array}$ & 77,752 & 4,794 \\
\hline Computation time (min) & 111 & 21 \\
\hline $\begin{array}{l}\text { Peak memory usage of all } \\
\text { processes (Mbyte) }\end{array}$ & 176.9 & 17.1 \\
\hline Mean difference (\%) & \multicolumn{2}{|c|}{0.1} \\
\hline
\end{tabular}

수준으로 감소했다. 반면에 ISAR 결과상 오차는 $0.1 \%$ 로, 예시 1 과 마찬가지로 정확도는 유지되면서 계산 자원이 대폭 줄어든 것을 알 수 있다.

\section{4. 결 론}

본 논문에서는 레이다흡수체가 부분 코팅된 전기적 대형물체의 산란 기여도 분석을 위해 ISAR 이미지 결 과를 도출하였고, 전체 구조를 해석한 경우와 동일한 결과를 도출하는 대신 계산 자원과 시간을 현저히 줄 일 수 있는 우회 해석 방법을 제시하였다. 해당 방법 을 통해 레이다 표적의 $\mathrm{PEC}$ 형상에 대한 해석 결과 를 사전에 확보하고 있다면, 흡수체 코팅부위만을 따 로 계산하여 등가 전류 값을 구한 후 $\mathrm{PEC}$ 형상 등가 전류 값 중 해당 부위의 값을 대체하여 전체 구조의 등가 전류 값을 재구성 할 수 있다. 이를 이용하면 다 양한 전기적 대형 레이다 표적의 해석에 범용 적으로 적용할 수 있는 장점이 있다.

본 논문에서 제안하는 방법을 통해 ISAR 기반 hotspot 분석의 효용성을 검증하였지만, $\mathrm{PO}$ 근사 기법 자 체의 부정확성을 개선할 필요가 있다. 향후에는 광선 추적법(Ray-tracing) 등의 개선 방안을 적용해 다중 반 사의 영향을 고려하여 정확도를 향상시킬 것이다.

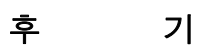

This work was supported by the Agency for Defense Development of Korea under Contact UD170044JD.

\section{References}

[1] C. Mitrano, A. Balzano, and M. Bertacca, "CFRPBased Broad-band Radar Absorbing Materials," IEEE Radar Conference, May, 2008.

[2] H. B. Baskey, M. J. Akhtar, and T. C. Shami, "Investigation and Performance Evaluation of Carbon Black- and Carbon Fiber-based Wideband Dielectric Absorbers for X-band Stealth Applications," Journal of Electromagnetic Waves and Applications, Vol. 28, No. 14, pp. 1703-1715, 2014. 
[3] S. Padhy, S. Sanyal, R. S. Meena, R. Chatterjee, and A. Bose, "Characterization and Performance Evaluation of Radar Absorbing Materials," Journal of Electromagnetic Waves and Applications, Vol. 27, No. 2, pp. 191-204, 2013.

[4] C. Ozdemir, Inverse Synthetic Aperture Radar Imaging with MATLAB Algorithms, A. John Wiley \& Sons, Inc., 2012.

[5] S. Kim, K. Nikitin, and M. Ka, "Generation of ISAR Image for Realistic Target Model Using General Purpose EM Simulators," The Journal of Korean Institute of Electromagnetic Engineering and Science, Vol. 26, No. 2, pp. 189-195, 2015.

[6] J. Song, C.-C. Lu, and W. C. Chew, "Multilevel Fast Multipole Algorithm for Electromagnetic Scattering by Large Complex Objects," IEEE Transactions on Antennas and Propagation, Vol. 45, No. 10, pp. 1488-1493, 1997.

[7] B. Kolundzija, M. Tasic, D. Olcan, D. Zoric, and S. Stevanetic, "Full-Wave Analysis of Electricaaly Large Structures on Desktop PCs," in Coputational Electromagnetics International Workshop(CEM), Izmir, Turkey, pp. 122-127, 2011.

[8] Y. Yan, Y. Zhang, C.-H. Liang, H. Zhao, and D. Garcia-Donoro, "RCS Computation by Parallel MoM Using Higher-Order Basis Functions," International Journal of Antennas and Propagation, Vol. 2012, pp. 1-8, 2012.

[9] M. Borgese, P. Usai, F. Costta, and A. Monorchio, "Fast RCS Prediction of Electrically Large Targets Coated with Radar Absorbing Materials," 12th European Conference on Antennas and Propagation, London, UK, April, 2018.

[10] H. Zeng, X. Zhao, Q. Su, Y. Zhang, and H. Li, "Fast Coating Analysis and Modeling for RCS Reduction of Aircraft," Chinese Journal of Aeronautics, Vol. 32, No. 6, pp. 1481-1487, September. 2018.

[11] K. Zhang, C. Wang, and J. Jin, "Broadband Monostatic RCS and ISAR Computiation of Large and Deep Open Cavities," IEEE Transactions on
Antennas and Propagations, Vol. 66, No. 8, pp. 4180-4193, August, 2018.

[12] C. Ozdemir, B. Yilmaz, and O. Kirik, "PRediCS: A New GO-PO-Based Ray Launching Simulator for the Calculation of Electromagnetic Scattering and RCS from Electrically Large and Complex Structures," Turkish Journal of Electrical Engineering and Computer Sciences, Vol. 22, No. 5, pp. 12551269, January, 2014.

[13] K. S. Kim, E. J. Yang, C. H. Kim, and S. C. Park, "Improvement of ISAR Autofocusing Performance Based on PGA," Journal of the Korea Institute of Military Science and Technology, Vol. 17, No. 5, pp. 680-687, 2014.

[14] K. Kwon, J. Yoo, M. Chung, and T. Yoon, "A Development of the Analysis Technique for Radar Target Signiture and the Software Using RCS/ISAR," Journal of the Korea Institute of Military Science and Technology, Vol. 7, No. 2, pp. 88-99, 2004.

[15] C. A. Balanis, "Antenna Theory, Analysis and Design," 3rd ed. Chichester, Wiley Interscience, US, 2005.

[16] W. C. Gibson, "The Method of Moments in Electromagnetics," 2nd edition, CRC Press, US, pp. 25-58, 2015

[17] M. Hossein, Z. Abolghasem, and H. F. Zaker, "Modified Physical Optics Approximation for RCS Calculation of Dielectric Coated PEC with Axial Symmetry," Journal of Electrical and Computer Engineering Innovations, Vol. 3, No. 2, pp. 115122,2015

[18] X. Tan, M. Fang, and Z. Huang, "RCS Simulation and ISAR Imaging of Coated Targets," IEEE International Conference on Computational Electromagnetics, March, 2019.

[19] J. Kim, S. Lee, and C. Kim, "Comparision study on the Effect of Carbon Nano Materials for SingleLayer Microwave Absorbers in X-band," Composites Science and Technology, Vol. 68, No. 14, pp. 2909 -2916, November, 2008. 